\title{
Bichos de pensamento: a lírica meditativa de Renato Suttana
}

\author{
Beasts Made of Thought: Renato Suttana's Meditative Lyric \\ Animales de pensamiento: la lírica meditativa de Renato Suttana
}

Ronald Silva Robson

\section{Resumo}

Ainda publicada apenas por editoras de pequeno porte, a poesia de Renato Suttana destaca-se pelo alto grau de elaboração formal e audácia reflexiva. Um dos principais veios de sua produção está em seus bestiários. Os bichos que comparecem em seus livros são delineados - segundo defendemos - a partir de uma visada fenomenológica, que os retira do transcurso temporal para melhor apreendê-los. O procedimento se torna ainda mais complexo com a fixação de bichos inteiramente imaginários: nesse caso, o questionamento sobre a possibilidade de representação do animal se torna um questionamento sobre a própria finalidade da poesia.

Palavras-chave: Renato Suttana, bestiário, fenomenologia, poesia.

\begin{abstract}
Restricted to the limited circle of small publishing houses, Renato Suttana's poetry shows a high level of formal acuity and boldness of thought. One of its main features is the practice of poetic bestiaries. The beasts that appear in Sutanna's books are situated - as we argue throughout the paper - by a phenomenological perspective that displaces them from the course of time in order to better apprehend them. This procedure achieves a higher level of complexity with the fixation on entirely imaginary beings: in this case, the question of the possibility to represent animals becomes a question about the purpose of poetry.
\end{abstract}

Keywords: Renato Suttana, bestiary, phenomenology, poetry.

\section{Resumen}

Hasta ahora restringida a la esfera de las pequeñas editoras, la poesía de Renato Suttana se destaca debido a su elevado grado de refinamiento formal y su audacia de pensamiento. Una de las principales vertientes de su producción son los bestiarios. Los animales son vistos en los libros de Suttana - según defendemos - con ojos de fenomenólogo que los aisla del transcurso temporal para mejor fijarlos. Eso modo de proceder se muestra aún más complexo en el caso de fijación de seres enteramente imaginarios: la pregunta por la posibilidad de representación de lo animal se confunde con la pregunta por la propia finalidad de la poesía.

Palabras-clave: Renato Suttana, bestiário, fenomenologia, poesía.

A poesia de Renato Suttana, há quase duas décadas em circulação em tiragens limitadas e quase secretas, ainda está à margem das grandes editoras. É difícil aferir a causa do estranho fenômeno: se é uma determinação pessoal do autor prosseguir correndo por fora, a fim de construir sua obra literária longe de qualquer vida literária, ou se é apenas mais um infeliz desencontro de nossa costumada cegueira editorial, incapaz de enxergar a luminosidade discreta de uma poesia que não descarta a tradição nem a inventividade (do soneto ao verso livre, dos temas da vida contemporânea aos topoi clássicos) e que não vende no atacado o que o leitor não for capaz, por si só, de comprar caro no varejo do trato direto com uma lírica que exige reflexão.

Natural de Barroso (MG), Suttana é professor da Universidade Federal da Grande Dourados e autor de uma vintena de títulos de poesia. Estreou relativamente tarde (para quem escreve poemas e nasceu em 1966) com Visita do fantasma da noite (2002) e, desde então, publicou uma

\footnotetext{
* Universidade Estadual de Campinas (Unicamp), Campinas, SP, Brasil. (Dorcid.org/0000-0002-9380-7713. E-mail: ronaldsrobson@gmail.com
} 
quantidade constrangedora (a palavra tem aqui bom sentido) de livros, plaquetes e e-books. Vale mencionar Fim do verão (2009a), Rapinário (2015a), Quando me abriram portas (2017a), Altiplano (2017b) e Música de pianola (2018a) como exemplares de sua produção lírica. Mas o poeta também achou de se dedicar a uma lírica mais torta, mais política e mais afeita à ordem do dia, da qual emergiram os poemas satíricos (sonetos, em sua maior parte) de Indigestos e purgativos (2016a) e de Lições de economia (2018b). A tiragem de apenas 50 exemplares não permitiu até o momento que a crítica aquilatasse os logros e malogros do poema épico em oitava rima Opinionautas: a educação dos cavalos falantes, cujos dois volumes publicados (2012) abrangem em mais de 400 páginas os livros 1 e 2 da obra, aos quais se somarão ainda um terceiro e quarto livros. É o relato da viagem fantástica da trupe de Estragoneias, o qual, sob as bênçãos de Baal, navega por mares hoje por todos navegados - os da vida virtual inflada de falatório, discussão, opinião - rumo à ilha de Cuba, não sem antes aportar em lugares improváveis como a rica e ostentadora Pipilândia, a Abobrínea, a Tacitúrnia e a Desineia, terra das modelos, em companhia de gente tão variada e esquisita como o poeta Anacruso e o mestre de gramática Aquiles.

Suttana mais parece o nome de um coletivo que assina livros de poesia em série. Pior: tem ainda a desfaçatez de se dedicar ao teatro, com Inundação (2015b), à tradução (Blake, Baudelaire, Leopardi, Lovecraft, entre outros) e ao ensaio literário, como nos títulos João Cabral de Melo Neto: o poeta e a voz da modernidade (2005b) e Uma poética do deslimite: poema e imagem na obra de Manoel de Barros (2009b).

Sua produção poética, que não descuida do apuro formal, mas nem por isso se petrifica em datado formalismo, talvez tenha várias portas de entrada, mas uma parece ser tão cara ao autor, e leva a resultados tão formidáveis em matéria de realização poética e vigor meditativo, que logo se impõe como privilegiada: bichos, isto é, poemas escritos como registros de um bestiário.

\section{Bestiários na poesia brasileira contemporânea: alguns apontamentos}

Segundo W. H. Auden (apud Cavalcanti, 2012, p. 349), são cinco as maneiras pelas quais os animais participam da poesia: i) na condição de seres antropomórficos, isto é, como personagens que agem e falam, caso das fábulas; ii) como fonte de uma qualidade que é atribuída a alguém ou algo por meio de símile (exemplo: "bravo como um leão"); iii) como fonte de alegoria, caso do "cordeiro de Deus", do bode que simboliza o demônio etc.; iv) como meio de evocação de situações vividas, com o estabelecimento do paralelo entre alguma característica do animal e aquela circunstância específica (uma vítima pode ser comparada, por exemplo, ao cervo que é abatido pelo caçador); e $v$ ) por meio de simples afeto do autor (ou pelo menos de sua persona lírica) pelo bicho.

Essa última categoria parece ser a predileta dos poetas modernos, como no caso de Os gatos, de T. S. Eliot. O bicho é apreendido sem maiores pretensões simbólicas, apenas como ocasião para o estudo de determinados elementos. Pode-se constatar algo dessa mesma aspiração na poesia brasileira contemporânea. Veja-se Figuras metálicas (2005), de Cláudio Daniel, que traz poemas cujos títulos simulam entradas de verbetes dos bestiários tradicionais, os quais tinham por fontes principais a História natural de Plínio o Velho, na antiguidade, e o tratado grego Physiologus, de autor indeterminado, escrito em algum momento entre os séculos I e III, cuja difusão se deu por meio das glosas que dele faz Isidoro nas Etimologias (século VII). Diferentemente do que se pretendia nessas obras fundadoras da bestialogia ocidental, nas quais a ciência natural se conjugava à elucubração metafísica tendo os animais por símbolos, o livro de Cláudio Daniel não tem qualquer propósito inspirador: "Em lugar de finalidades moralizantes, a pura descrição insólita, a criação de imagens fantásticas", como dizem Eduardo Jorge de Oliveira e Maria Elisa Rodrigues Moreira (2010, p. 6) em artigo de recensão de bestiários na literatura brasileira contemporânea, na qual também destacam a produção de Ronald Polito, Nuno Ramos e Wilson Bueno. Por sinal, o Jardim zoológico (1999) de Bueno é objeto de rápido, mas interessante estudo de Maria Esther Maciel, que nele vê "um compósito de elementos mitológicos, lendas indígenas, referências culturais brasileiras e hispanoamericanas", de modo que "os animais de Bueno reatualizam, por uma perspectiva 
transcultural, tanto os bestiários da tradição ibérica quanto as coleções zoológicas de Borges e as lendas indígenas brasileiras" (2007, p. 149).

Destacam-se, em meio à produção contemporânea, as animálias reunidas por Marco Lucchesi na segunda parte do seu Meridiano celeste \& Bestiário (2006). Os 24 animais ali apreciados têm marcações culturais e geográficas bem definidas, as quais não se limitam a um único quadrante étnico e simbólico do globo. A girafa é dos muçulmanos: "Passeia / nas páginas / do alcorão sagrado". O beija-flor é dos índios: "deus e senhor / do mundo / guarani". O besouro será bizantino: "protomártir / das cinzas / de Bizâncio". A águia será da antiguidade pagã: "os ventos / de Hölderlin // [...] anunciam // na miragem // das águias / a vinda / luminosa dos antigos / deuses" (Lucchesi, 2006, p. 96, 99, 106, 118). Tudo guiado por um princípio de espelhamento entre geografia, história e símbolo. Não é de estranhar que se mencione o leão como "fera sublime / das analogias" (Lucchesi, 2006, p. 117) - é mesmo a analogia que preside a confecção desses poemas.

De sua parte, Suttana, cuja produção é inteiramente avessa à tentação da analogia - e por isso se distancia de Wilson Bueno e Marco Lucchesi, ao mesmo tempo que se aproxima muito minimamente de Cláudio Daniel -, dedicou até o momento quatro livros a bichos: Bichos (2005), Outros bichos (2011), Bichos imaginários (2013) e Fauna \& Cia. (2016b). Sua aspiração não é fabulatória, não se compraz na busca de meros símiles, e tampouco é simbólica, nem evocatória, nem meramente casual. Seu interesse principal é de ordem quase metafísica e reside nos procedimentos escolhidos para apreender poeticamente os objetos (isto é, os bichos).

A seguir daremos atenção a dois títulos de Suttana, Bichos e Bichos imaginários. Fauna \& Cia. situa-se à parte por ser livro de sátira e alegoria política, e de Outros bichos nada podemos dizer em razão de uma aparentemente invencível dificuldade de acesso ao livro.

\section{Bichos: investigações do instante}

Bichos apresenta 23 poemas, de versos curtos (geralmente não ultrapassam a sétima sílaba), como breves retratos de bichos extraídos de sua existência comum e elevados a uma espécie de formalidade exemplar (algo disso também está presente nas ilustrações de Nicolau Saião que acompanham os poemas). Os bichos de Bichos são estáticos - o truque, nos poemas, é mostrálos, justamente por isso, extáticos em sua conformação.

Um procedimento formal muito a propósito, aí, são os muitos cortes dos poemas por parênteses, que põem em suspensão algum aspecto do bicho, ou que cortam um seu aspecto com um comentário sobre alguma nota existencial mais saliente que ele guarde. A barata, logo após a constatação de que surgira "De repente / na parede branca", merece a anotação extemporânea: "(Provavelmente / absorvida / nalgum negócio escuso: // inimaginável.)" (Suttana, 2005, p. 19). O leão, que "é um centro de violência", é logo em seguida identificado como "(um caldeirão solar // no centro / de um vazio)" (Suttana, 2005, p. 13). Ou ainda, para dar um último exemplo, a águia, da qual, antes de saber qualquer outra coisa, é o leitor lateralmente informado de que "(só as vejo em livros, mas sei / que são fragmentos alados / de morte e beleza)" (Suttana, 2005, p. 31).

O que temos aí são pequenas fenomenologias - breves poemas de perquirição que, contudo, pouco indagam. Sua marca é a aceitação das formas animais que se oferecem. Não se trata aqui de fenomenologia no sentido kantiano de separação entre aquilo que é a coisa para além da percepção sensória e o que ela é para a sensibilidade humana; trata-se de fenomenologia no sentido husserliano de afirmação do modo de apresentação da coisa à consciência: pouco importa se real ou irreal, se mais exata ou menos exata, o fato é que a coisa tem uma forma própria de apresentar-se, a qual requer investigação em si mesma, sem que se a tome como sintoma (mero "fenômeno" ou aparência) de alguma outra coisa que se considere ou suspeite mais essencial (Abbagnano, 2012, p. 510-512).

Em Bichos, portanto, os animais são delineados em sua fenomenalidade, e especialmente no que possuem enquanto signos de natureza visual. Os animais são assim percorridos pelo olho num átimo, num perceber de quase pura tridimensionalidade, ou, ainda, só de espacialidade. Não à toa, muitas vezes os bichos comparecem como não mais que superfície plástica, como não 
mais que cor escura e impenetrável. O besouro é "grosso / caroço // de preto"; o lagarto surge como "mancha negra / no muro"; a pulga "é um ponto negro / de desassossego" (Suttana, 2005, p. 26, 29, 39, grifo nosso).

De nada adianta procurar o que há de "sentido" no bicho. Da abelha se diz que "Inutilmente procuraremos / nela / uma lição"; o rinoceronte, descrito como coisa de máxima opacidade, "É um velho tronco / desajeitado / sobre quatro patas"; o único bicho do qual se diz que nos ensina algo é a serpente, mas ela precisamente "nos ensina a simplicidade // fria / de ser apenas / o que se é", elemento em que também é versado o porco-espinho, ser que simula ter "atingido o ponto mais extremo / em que se contenta em ser / o que é: // uma forma intratável - / uma / aparência inabordável, // e semelhante a coisa nenhuma" (Suttana, 2005, p. 15, 33, 31, 47, grifo nosso). Ou seja: o bicho apenas é algo enquanto ser existente e mais nada, quase como se quisesse só existir e jamais ser conhecido, de modo que assim não nos oferece outra via de acesso a ele que não essa sua opacidade, essa sua dificuldade intrínseca de apreensão.

O mais completo poema do livro, quanto à enunciação desse problema de "conhecimento poético", é "A galinha (I)", no qual a existência do bicho é ofertada a nossos olhos como carente de interesse (vejam-se os dois últimos versos) e anterior a qualquer indagação nossa acerca de sua natureza (a precedência do ovo ou da galinha mencionada entre a segunda e quarta estrofes):

Admiramos o modo

como se equilibram

sobre duas patas.

(E não nos lembramos de que

já o faziam

muito antes de nos ocorrer

a trivial pergunta

acerca de terem sido

precedidas

pelos seus próprios ovos.) -

E olham,

e veem,

e com bicadas certeiras

apanham

o invisível

numa ansiedade franca.

Estão aí simplesmente.

(Píndaro não lhes dedicaria

uma ode.) (Suttana, 2005, p. 27-28).

Em "A galinha (II)", é dito francamente o que apenas se insinuara antes sobre esse bicho: "nada simboliza" (Suttana, 2005, p. 53). Como se vê, o eu que fala em Bichos não tem muita afeição pela tradicional propensão simbólica dos bestiários.

\section{O instante alongado}

As descrições dos bichos como meros fenômenos que aparecem à sensibilidade do eu lírico tendem, justamente em razão dessa sua natureza de dados atomizados, a se traduzir em um fechamento do transcurso temporal em torno do ser retratado. Os bichos são assim emoldurados num instante que se alonga sem que nada suceda. O leão não possui circunstância alguma, está como que retirado do fluxo temporal: "Nada se forma // à sua volta". A abelha se encontra, 
solitária, como coisa inteiramente à parte do dia no qual se insere: "seu zumbido // é só um deserto medido, / alado, / à luz do dia". O tubarão, que é "visto / na televisão", não avança nem retrocede, apenas se sustenta em seu espaço próprio: "A flutuar / insone/ pelo amplo mar" (Suttana, 2005, p. 13, 15, 51). O lagarto é tomado como bicho paradigmático desse tempo morto:

(Congelado no instante

digere

a sua própria eternidade:

calcula

o seu ouro

em silêncio.) (Suttana, 2005, p. 29).

O poeta tenderá a compreender esse modo de existência ("congelado no instante") de maneira ainda mais alargada: se o tempo é transcurso, é um ir adiante que não cessa e, se por outro lado, o bicho é algo de estático e inerme, nasce uma oposição entre o modo geral de existência e o modo particular de apresentação de cada bicho. Assim, abre-se uma cisão entre o bicho e o mundo circundante. "No mundo da ferocidade / o gato carrega, sereno, / a sua verdade"; "na parede branca / a barata preta"; "O porquinho-da-índia / no poço da jiboia / é um abandonado da sorte"; o elefante tem "um pé no / instante / e outro no / que não se sabe" (Suttana, 2005, p. 17, 19, 23, 35).

\section{Bichos imaginários: imaginar o inexistente}

Diante do que acabamos de expor sobre Bichos, poderíamos, com razão, estranhar o título Bichos imaginários: já não eram aqueles primeiros bichos em larga medida imaginários, além de imaginosos? Claro que a pulga, o rinoceronte e a galinha são bichos que de fato existem, mas o poeta não os apresenta, sobretudo, sob o aspecto de coisas imaginadas? Dito de outro modo, os bichos de Bichos são exibidos despidos de toda sua naturalidade, numa temporalidade mais lenta (o instante alongado de que falamos há pouco) e com acentuação desmedida de seus traços distintivos. Contam mais pela sua forma quando imaginados do que pela sua forma de manifestação como coisa existente. Em que sentido, portanto, os bichos apresentados nesse outro livro são especificamente imaginários?

Vejamos. Os Bichos imaginários de Suttana provêm em parte da tradição luso-brasileira moderna: "lebres de vidro", "leões alados", "besouro rútilo" e "sapo parnasiano" se originam, respectivamente, de versos de João Cabral de Melo Neto, Mário de Sá-Carneiro, Cassiano Ricardo e Manuel Bandeira, que são apresentados em epígrafe. Outros parecem aludir vagamente a algumas personagens, como o "gato risonho" (o Gato de Cheshire, de Alice no País das Maravilhas, de Lewis Carrol; ou Behemot, o gato negro gigante de Mestre e Margarida, de Mikhail Bulgákov), e outros ainda fazem apenas ressoar certa tradição de imagens e temas a eles associados, caso dos "tigres invisíveis" (William Blake) e dos "corvos de alumínio" (Edgar Alan Poe). Especialmente estrambóticos, são bichos como a "girafa de calças", o "cavalo de pano", o "rinoceronte do vento", as "cigarras engrenagens", os "bois de sombra" e as "traças eruditas".

Esses bichos, imaginários que são, convidam a fantasia a completá-los. Não é por outro motivo que o poeta já previne o leitor em "A ninhada", poema que tem por subtítulo "quase um prefácio" e que abre o livro: "um grande ponto de exclamação / dividirá ao meio / a tua confusão" (Suttana, 2005, p. 6).

Se no livro anterior o esforço era quase de ascese da palavra perante o olhar (de certo modo, o problema do imaginário estava camuflado de problema do olhar), aqui, por outro lado, é o aspecto discursivo, dialógico, que sobressai: esses poemas menos mostram que falam, mais exprimem a expressão da surpresa do que imprimem a marca de uma forma. Vejam-se os versos iniciais de "As lebres de vidro (I)", dedicados a esse bicho imaginado num poema de João Cabral de Melo Neto:

As lebres de vidro

fazem-nos sonhar:

levam nossos medos, 
levam nossos nomes,

levam nossa fome

à orla indiferente

do impreciso mar.

Os poemas podem agora indagar pelo que têm de imaginário os bichos que descrevem, o que é só um modo de perguntar como se imagina o imaginável, isto é, como se introduz a cisão e a comunicação entre o inimaginável, além de inexpressável, e o impossível, porém imaginável e expressável:
A lagartixa de asas
foi confundida
internacionalmente
com um dragão.
Quem nunca viu um dragão
não sabe o que é um dragão.
Quem nunca viu
uma lagartixa
não sabe o que é uma lagartixa.
Quem nunca viu
a lagartixa de asas
não sabe o que é
uma lagartixa de asas.
(E não sabe que é só
uma pequena lagartixa de asas.)

Esta é uma formulação do problema (outra diz respeito aos tigres invisíveis: "Os tigres invisíveis / percorrem em silêncio / os arredores. // (Quem acha que os conhece / está enganado: / quem pensa que já os viu // nada entendeu.)”). Formulações de problemas são coisa abstrata. Mas há formulações menos problemáticas, em aparência, e por isso menos abstratas também em aparência (ao menos). Como no caso do convite que nos é feito a imaginar o trote do cavalo de pano: "Ouçam o trotar / do cavalo de pano, / quando dispara, feliz, / pelas estradas de pano".

\section{Bichos que existem porque não existem}

Uma marca temática decorrente desse impasse imaginativo é que os poemas desconstroem os bichos propostos à medida que os constroem. É um verdadeiro achado de Suttana o animal que escolheu para bem resumir o tema: "O gato de Schrödinger".

Como se sabe - ou, pelo menos, como se pensa saber em meios não científicos quando se fala de algumas questões científicas -, o gato em questão é um produto puramente hipotético e mental proposto pelo físico teórico austríaco a fim de ilustrar problemas da física quântica ligados ao "princípio da incerteza" de Heisenberg. O gato, colocado dentro de uma caixa selada, vedada a todo contato humano, será exposto ou não a veneno a depender de se um contador Geiger registrar ou não oscilação numa minúscula quantidade de substância radioativa. A ideia central é a de que, até o momento em que haja intervenção humana (abrir a caixa e averiguar a situação do animal), as condições de "vivo" e "morto" estão superpostas, assim como os estados quânticos. É um gato que é e não é, que existe e não existe, que vive e morre ao mesmo tempo. Mas, escreve Suttana, "É um gato qualquer / e ao mesmo tempo / um excelente gato, / como todos os gatos". Esse "gato único" é também um "gato qualquer"; "É um gato que se pode / no mesmo lance / dar de presente a uma menina / e ter em casa / como bicho de estimação",

pois é no mesmo instante

preto e pardo,

branco e preto,

o gato

e seu contrário 
em iguais proporções

na flecha do tempo (Suttana, 2013, p. 33-34).

Do mesmo modo, como afirmar a presença de uma "serpente-corda" sem, no mesmo ato, correr o risco de afirmar uma dubiedade quanto à sua conformação? "Aquilo que se vê, à distância, / pendurado ao pescoço / do homem / / pode ser, no mínimo, / quatro coisas: / uma gravata, // uma corda, / uma serpente / ou uma serpente-corda". O salto imaginativo vem em seguida, com a possibilidade de que a coisa vista seja mesmo aquilo que se quer que ela seja: "Em se confirmando / a última hipótese, / cabe ao homem / / ou desistir de suas pretensões / ou aceitar / a realidade" (Suttana, 2013, p. 32). Ou: caso se trate, de fato, de um objeto de percepção (construído mentalmente) tão dúbio e improvável quanto uma "serpente-corda", a inteligência só pode optar pela abdicação de qualquer tentativa de definição ou aceitar a indefinição como uma nota do próprio objeto. A indefinição do bicho em questão, portanto, não é elemento impeditivo à sua construção; ao contrário, é algo que justamente propicia o acesso ao bicho. Aquilo que desconstrói e desvirtua o projeto inicial do bicho é o que por fim dá base à sua existência mental.

Uma pergunta de natureza filosófica que não se pode responder aqui, mas que é sugerida pelo poema, seria esta: na verdade, não poderíamos dizer que tudo que experimentamos traz alguma porção de indefinição, e assim a "serpente-corda" se distinguirá dos demais objetos materiais apenas por uma diferença quantitativa (é mais indefinida), e não qualitativa? O século XX nos deu muitas filosofias que receitam uma parcimônia perante o conhecimento, uma admissão da impossibilidade de atingir todos os estratos de sentido de um objeto de percepção. Wittgenstein é bom exemplo disso, e há mesmo uma proposição sua que bem calha a muitos versos de Suttana: "Fazemo-nos figurações dos fatos" (Wittgenstein, 1968, p. 59). Poderá haver dúvida acerca do quanto o modelo de figuração corresponde à realidade, mas não poderá haver dúvida quanto à figuração em si mesma (o que afirmamos conscientes do risco de estar interpretando de maneira demasiado fenomenológica aquela frase do Tractatus LogicoPhilosophicus); pelo menos esse estrato mínimo de certeza deve ser pressuposto.

O que há de mais interessante no modo como esse tema se imiscui na poesia de Renato Suttana está no fato de que ele não partilha, ao que parece, de nenhuma "poética da indefinição", de nenhuma releitura simbolista, por exemplo, da atividade do poeta, ou de nenhuma adesão radical a estéticas de "obra aberta". A indefinição dos entes é, no caso de um poema como "A serpentecorda (II)", alcançada por meio de marteladas de objetividade que levam objetivamente ao reconhecimento da insuficiência ou indefinição de qualquer descrição que se pretenda exaustiva.

Os bichos imaginários de Suttana são definíveis porque indefiníveis, são existentes porque inexistentes.

\section{Estratos de sentido}

Uma estrutura sintática preferida nesses poemas é o empilhamento de versos como apostos, interligados por anáfora (repetição de palavras ou expressões no início de versos sucessivos). São como camadas de expressão do imaginário que vão se somando, até que uma resolução possível e passageira aconteça. O procedimento pode ser flagrado em "O gato risonho". Após a primeira estrofe na qual se enuncia que "Não há coisa mais estranha / que um gato risonho", segue-se uma estrofe toda anafórica:

Na escuridão da noite, quando a chuva cessou, quando voltamos do teatro, sobre a linha de um muro, quando abrimos o portão, quando abrimos a janela ou espiamos através da fresta, não há coisa mais estranha que um gato risonho (Suttana, 2013, p. 12). 
Coisa idêntica se pode dizer de "Os Rinocerontes do Vento". "Há muito tempo venho pensando / nos rinocerontes do vento", e eis alguns desses pensamentos: "Pensei que as nuvens fossem rinocerontes, / pensei que as emanações da névoa / fossem rinocerontes"; pensou ainda "que a fumaça das fábricas / fosse rinocerontes. / Mas minha teoria estava errada" (Suttana, 2013, p. 21), último verso esse que, como o leitor pode notar, é mais um exemplo do artifício de construção autocontraditória que sustenta formalmente grande parte dos poemas de Bichos imaginários.

O procedimento formal de acúmulo, de superposição de estratos de enunciado, não é gratuito; ao contrário, justifica-se por uma necessidade intrínseca da matéria tratada. Em Bichos havia um esforço para ouvir a voz das coisas, ou melhor, para fixar seus delineamentos com o máximo de objetividade. É o império da coisa sobre a inteligência. Já em Bichos imaginários há esforço para falar, falar e falar sobre coisas livremente criadas, a fim de ver se o próprio e intransitivo exercício do pensamento é capaz de apontar para alguma existência, para algum sentido. É o império da fala, da inteligência, sobre a coisa - o império dos imaginários sobre os bichos. O visto não manda mais no olho, é a fala que ordena o dito, dito que não se sabe se é apenas produto da linguagem ou coisa subsistente por si mesma.

Os poemas se orientam pela soma de informações que surgem como impressões intelectivas bem poucas vezes de natureza sensória - sobre bichos fantásticos. Muitas dessas impressões surgem em construções verbais que simulam objetividade, mas que, na verdade, por sua própria e variada sucessão, constituem-se em diferentes maneiras de cercar um mesmo elemento. Por exemplo, "Os cães de guerra / declararam guerra / ao sol e à lua"; mais ainda, "Declararam guerra / ao mar e à espuma"; e também, "ladrando ao vento, / declararam guerra / ao seu assobio", e ainda "ladraram à nuvem / e à viração" (Suttana, 2013, p. 14). A "serpente-corda", por sua vez, "serve para amarrar / um sapato de areia"; "serve para devorar / o pássaro dos minutos / e os filhotes do vácuo"; e "Serve para amarrar / num único fardo / todos os propósitos / e as datas". Não é tudo. Entre suas outras serventias está a de que "Nela poderia se enforcar / um espantalho, / poderia se equilibrar / a sombra da bailarina", e a de que "com ela um homem magro / poderia atar, perfeitamente, / num único todo / a dispersão dos seus sonhos / fugindo" (Suttana, 2013, p. 26-27).

É como se a inteligência, na tentativa de apanhar o que a imaginação propõe à revelia da existência do objeto tratado, lançasse simultaneamente várias redes: esta captará este aspecto, outra aquele outro, e assim por diante. A sintaxe e o princípio de construção anafórico são produtos de uma mente criativa flagrada no ato de fixar sua criação nos limites do ainda não criado e do criado (entendido como aquilo para além do qual nada mais é possível criar).

\section{Para que serve o bicho-poema}

Um aspecto do tratamento dado pelo eu lírico aos bichos é a conversibilidade entre ser imaginário e obra artística. Assim, o bicho se torna bicho-poema, e predicados quase sempre atribuídos à poesia, como a de sua inutilidade, sua condição de coisa imprestável para a vida prática, são transpostos para bichos imaginários. O poeta em nenhum momento se pergunta qual a finalidade de inventar bichos, mas afirma de maneira velada que essa atividade não difere, em substância, da atividade de escrever poesia. Tanto que, acerca dos "leões alados", pergunta-se: "Por que estão lá, seguros / de si mesmos, pousados / sobre a linha dos muros? / Não há ninguém que o explique, / nem quem o justifique" (Suttana, 2013, p. 29). De igual modo, seria possível dizer da poesia: não há ninguém que a explique, nem quem a justifique.

Esse é um registro que tem muito da autoimagem romântica do poeta como legislador secreto da realidade. Há em Bichos imaginários, contudo, outros registros em torno do mesmo tema que soam mais leves. Fala-se, por exemplo, da "palavra azul", improvável em si mesma e situada em lugar ainda menos provável: "Sob a orelha azul / da ovelha azul / lê-se, escrita em azul, / a palavra azul". Essa "ovelha azul / não tem - todos sabemos - / nenhuma primazia: as nuvens não pousam / no seu lóbulo / e as lebres não saltam / sobre o seu ombro". No entanto, é um trunfo para imprestáveis, para perdedores, para aqueles habituados ao inútil: "Quando o dia termina / e a fadiga domina, / quem não venceu o mundo / descansa o pensamento / naquela orelha" (Suttana, 
2013, p. 25). Perceba-se: é um descanso ao alcance de todos aqueles que não venceram o mundo; o poeta seria só mais um.

Mas como, perante a "palavra azul", não pensar na flor azul de Novalis? E com isso se volta às coisas nas quais tem autoridade o poeta. Ao elencar um personagem do mundo da eficiência (ou da ineficiência que, no entanto, se pretende eficientíssima), o poeta escreverá em outro poema ("A mosca de ouro") que "O funcionário / não tem autoridade / para mandar esculpir em ouro / o perfil da mosca" (Suttana, 2013, p. 29). Mas o poeta tem.

\section{Referências}

ABBAGNANO, Nicola (2012). Dicionário de filosofia. 6. ed. São Paulo: WMF Martins Fontes.

CAVALCANTI, Geraldo Holanda (2012). A herança de Apolo: poesia poeta poema. Rio de Janeiro: Civilização Brasileira.

LUCCHESI, Marco (2006). Meridiano celeste E bestiário. Rio de Janeiro: Record.

MACIEL, Maria Esther (2007). Bestiários contemporâneos: animais na poesia brasileira e hispanoamericana. Via Atlântica, n. 11, p. 145-153, jun. Disponível em: http://www.revistas.usp.br/viaatlantica/article/view/50671/54783. Acesso em: 17 dez. 2019.

OLIVEIRA, Eduardo Jorge de; MOREIRA, Maria Elisa Rodrigues (2010). Alguns bestiários na literatura brasileira contemporânea. Revista Crioula, n. 7, p. 1-13, maio. Disponível em: http://www.revistas.usp.br/crioula/article/view/55239/58868. Acesso em: 16 dez. 2019.

SUTTANA, Renato (2002). Visita do fantasma da noite. Guarapuava, PR: Edição do autor.

SUTTANA, Renato (2005a). Bichos. Guarapuava, PR: Edição do autor.

SUTTANA, Renato (2005b). João Cabral de Melo Neto: o poeta e a voz da modernidade. São Paulo: Scortecci.

SUTTANA, Renato (2009a). Fim do verão. Pará de Minas, MG: Virtual Books.

SUTTANA, Renato (2009b). Uma poética do deslimite: poema e imagem na obra de Manoel de Barros. Dourados, MG: UFGD.

SUTTANA, Renato (2011). Outros bichos. Florianópolis, SC: Edições Nephelibata.

SUTTANA, Renato (2012). Opinionautas: a educação dos cavalos falantes. Pará de Minas, MG: Virtual Books.

SUTTANA, Renato (2013). Bichos imaginários. Natal: Sol Negro Edições.

SUTTANA, Renato (2015a). Rapinário. Ilhéus, BA: Mondrongo.

SUTTANA, Renato (2015b). Inundação. Cascais, Portugal: Edições Bicicleta.

SUTTANA, Renato (2016a). Indigestos e purgativos. Dourados, MS: Ars.

SUTTANA, Renato (2016b). Fauna \& Cia. Dourados, MS: Ars.

SUTTANA, Renato (2017a). Quando me abriram portas. Ilhéus, BA: Mondrongo.

SUTTANA, Renato (2017b). Altiplano. Florianópolis, SC: Edições Nephelibata.

SUTTANA, Renato (2018a). Música de pianola. Dourados, MS: Ars.

SUTTANA, Renato (2018b). Lições de economia. Dourados, MS: Ars.

WITTGENSTEIN, Ludwig (1968). Tractatus Logico-Philosophicus. Tradução de José Arthur Giannotti. São Paulo: Companhia Editora Nacional; Editora da USP.

\section{Nota}

O presente trabalho foi realizado com apoio da Coordenação de Aperfeiçoamento de Pessoal de Nível Superior - Brasil (Capes) - Código de Financiamento 001. 